\title{
$\widehat{A}$ Madridge \\ madridge Journal of Case Reports and Studies \\ ntercon
}

Research Article

Open Access

\section{To Assess the effect of Osteoporosis on Survival Rate of Dental Implants-A Clinical Study}

\author{
Ashish Pandey ${ }^{\star}$, Harshad Mahant, Manoj KR Meena and Ankit Galav \\ Daswani Dental College and Research Centre, Kota, Rajasthan, India
}

\section{Article Info

\author{
*Corresponding author: \\ Ashish Pandey \\ Head \& Professor \\ Daswani Dental College and Research \\ Centre \\ Kota, Rajasthan \\ India
} \\ E-mail: ashishpande26@yahoo.co.in}

Received: September 30, 2019

Accepted: October 11, 2019

Published: October 18, 2019

Citation: Pandey A, Mahant $\mathrm{H}$, Meena MK, Galav A. To Assess the effect of Osteoporosis on Survival Rate of Dental Implants-A Clinical Study. Madridge J Case Rep Stud. 2019; 4(1): 151-153.

doi: $10.18689 /$ mjcrs- 1000140

Copyright: (c) 2019 The Author(s). This work is licensed under a Creative Commons Attribution 4.0 International License, which permits unrestricted use, distribution, and reproduction in any medium, provided the original work is properly cited.

Published by Madridge Publishers

\begin{abstract}
Background: Dental implants treatment has been used in the dentistry for the last few years. The present study was conducted to assess effect of osteoporosis on survival rate of dental implants.

Materials and methods: The present study was conducted on 54 osteoporosis patients of both genders who underwent dental implants in the last 5 years. Equal number of age and gender matched control was taken. Patients were recalled regularly after 6 months for the evaluation of mobility, pain, infection around the implant, presence of neuropathy and paresthesia. The level of bone loss at both sides of dental implants was measured.

Results: 5 patients in group I and 1 in group II had mobility, 4 in group I and 2 in group II had pain, 1 in group I had presence of neuropathy and 2 in group I and 1 in group II had paresthesia. In group I, most common bone type was III seen in 25 patients and in group II was type I seen in 24 patients. The difference was significant $(P<0.05)$. In group I there was $3.4 \mathrm{~mm}$ bone loss on mesial side and $3.6 \mathrm{~mm}$ on left side. In group II, there was $1.2 \mathrm{~mm}$ bone loss on mesial side and $1.4 \mathrm{~mm}$ on distal side. The difference was significant $(P<0.05)$. There were 12 dental implants failure in group I and 4 in group II. The difference was significant $(P<0.05)$.
\end{abstract}

Conclusion: Authors suggested that osteoporosis has great impact on survival rate of dental implant. There were more dental implants failures in these patients as compared to controls.

Keywords: Bone loss; Dental implant; Osteoporosis.

\section{Introduction}

Dental implants treatment has been used in the dentistry for the last few years. It has been proved better treatment modality in patients with missing teeth [1]. Removable denture has its limitation such as trauma of clasps to adjacent teeth and loosening of adjacent teeth. Fixed partial denture is better as compared to removable partial denture in terms of life of the prostheses as well as esthetics. The only drawback is the significant reduction of adjacent teeth which can lead to sensitivity of teeth [2].

Dental implants are preferred over other prostheses and are treatment of choice for dentists as well as for patients. They help to maintain bone, function, esthetics and phonetics, thus improving oral health-related quality of life. The demand for dental implants is continuously increasing, parallel to improvements in life expectancy since aging is accompanied by increased tooth-loss [3].

There are certain contraindications for dental implant therapy. Diabetes mellitus, hypertension, epilepsy, smokers and hyperthyroidism are few conditions which demands careful evaluation before deciding dental implant therapy in such patients. Osteoporosis is 
recognized as a common skeletal disorder characterized by low bone mass and micro-architectural deterioration leading to higher fragility and consequently to an increased risk of fracture. Approximately 75 million people all over the world are affected from osteoporosis [4]. The present study was conducted to assess effect of osteoporosis on survival rate of dental implants.

\section{Materials and Methods}

The present study was conducted in the department of prosthodontics. It comprised of 54 osteoporosis patients of both genders who underwent dental implants in the last 5 years. Equal number of age and gender matched control was taken. All patients were informed regarding the study and written consent was obtained. Ethical approval was obtained prior to the study.

General data such as name, age, gender etc. was recorded in case history performa. Patients were recalled regularly after 6 months for the evaluation of mobility, pain, infection around the implant, presence of neuropathy and paresthesia. Patients were subjected to intraoral periapical radiographs which were taken prior to the insertion of dental implants and subsequently follow ups. The level of bone loss at both sides of dental implants was measured. Results thus obtained were subjected to statistical analysis. $P$ value less than 0.05 was considered significant.

\section{Results}

Table 1 shows that group I was osteoporosis group and group II was control group. Both groups had 54 subjects each.

Table 1. Distribution of patients.

\begin{tabular}{|l|c|c|}
\hline Groups & Group I (osteoporosis) & Group II (Control) \\
\hline Number & 54 & 54 \\
\hline
\end{tabular}

Table 2 shows that 5 patients in group I and 1 in group II had mobility, 4 in group I and 2 in group II had pain, 1 in group I had presence of neuropathy and 2 in group I and 1 in group II had paresthesia. In group I, most common bone type was III seen in 25 patients and in group II was type I seen in 24 patients. The difference was significant $(P<0.05)$.

Table 2. Assessment of parameters in both groups.

\begin{tabular}{|l|c|c|c|}
\hline Parameters & Group I & Group II & P value \\
\hline Mobility & 5 & 1 & 0.01 \\
\hline Pain & 4 & 2 & 0.02 \\
\hline Neuropathy & 1 & 0 & 0.05 \\
\hline Paresthesia & 2 & 1 & 0.04 \\
\hline Bone quality Type I & 6 & 24 & 0.01 \\
\hline Type II & 8 & 16 & \\
\hline Type III & 25 & 10 & \\
\hline Type IV & 15 & 4 & \\
\hline
\end{tabular}

Table 3 shows that in group I there was $3.4 \mathrm{~mm}$ bone loss on mesial side and $3.6 \mathrm{~mm}$ on left side. In group II, there was $1.2 \mathrm{~mm}$ bone loss on mesial side and $1.4 \mathrm{~mm}$ on distal side. The difference was significant $(P<0.05)$ (Figure 1$)$.

Table 3. Bone loss in both groups.

\begin{tabular}{|l|c|c|c|}
\hline Parameters $(\mathrm{mm})$ & Group I & Group II & P value \\
\hline Bone loss (Mesial) & 3.4 & 1.2 & 0.01 \\
\hline Bone loss (Distal) & 3.6 & 1.4 & 0.02 \\
\hline
\end{tabular}

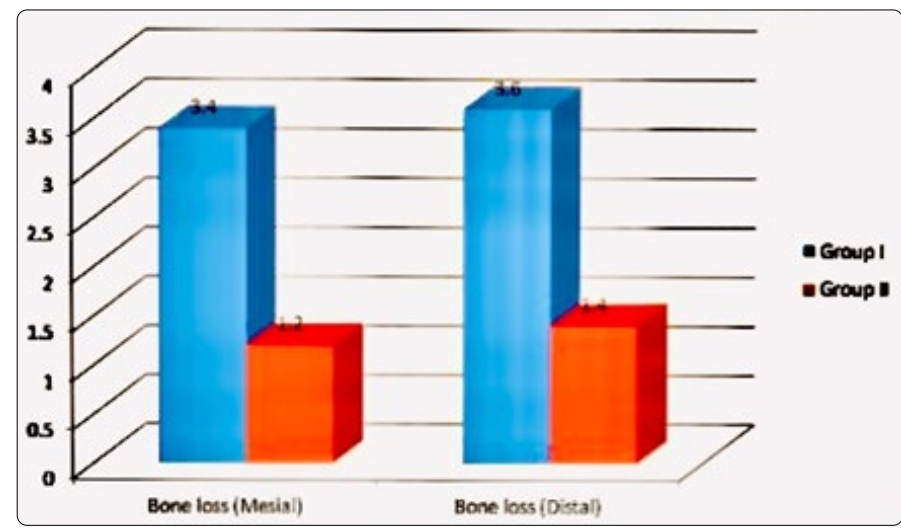

Figure 1. Bone loss in both groups.

Figure 2 shows that there were 12 dental implants failure in group I and 4 in group II. The difference was significant $(P<0.05)$.

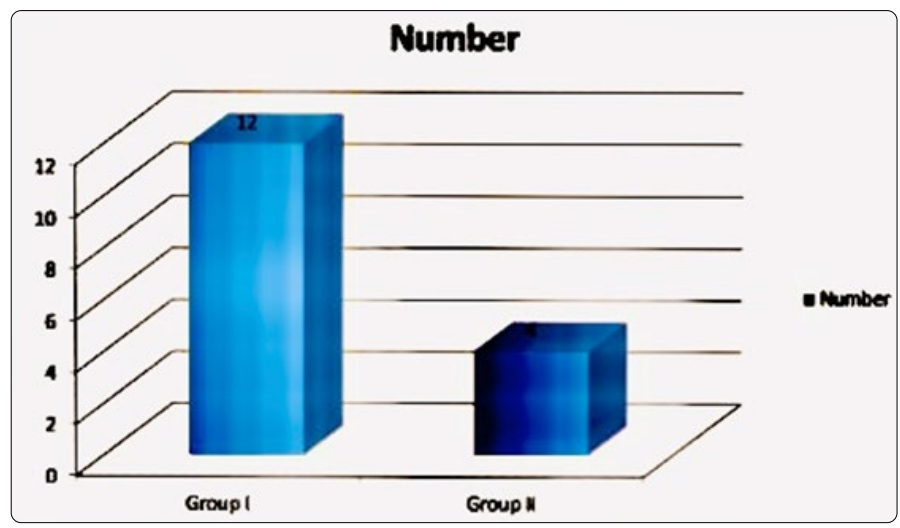

Figure 2. Failure dental implants in both groups.

\section{Discussion}

Patients with osteoporosis display a range of skeletal changes that may impact on the possibility of placing dental implants without the need for bone augmentation. Nuti et al. reported findings are a greater alveolar ridge resorption than average altered trabecular pattern in the anterior maxilla and posterior mandible erosions of the inferior border of the mandible as compared to unaffected individuals and increased resorption and thinning of the mandibular inferior cortical margin [5]. There are anecdotal reports that in patients with osteoporosis the incidence of maxillofacial fractures during the placement of endosseous implants is increased [6]. The present study was conducted to assess effect of osteoporosis in survival rate of dental implants.

In this study, we included 54 dental implants patients with history of osteoporosis. Equal number of controls was included in the study. We observed that 5 patients in group I and 1 in group II had mobility, 4 in group I and 2 in group II had pain, 1 in group I had presence of neuropathy and 2 in group I and 1 in group II had paresthesia. In group I, most common bone type was III seen in 25 patients and in group II was type I seen in 24 patients.

Although it is widely recognized that low bone mass is not the only determinant of bone fragility, the strength of the skeleton is influenced by other bone tissue properties, collectively named "bone quality" The mean change of bone remodelling pattern in osteoporosis patients resulted in 
perforation of trabecular plates and loss of cancellous trabecular elements with consequent bone mineral density [7]. Established risk factors for osteoporosis include older age; female gender; post-menopause; Caucasian or Asian race; a low body mass index; cigarette use; alcoholism; inadequate calcium and vitamin D intakes; physical inactivity; taking medications such as glucocorticoids and anticonvulsants; and anorexia nervosa [8].

We found that in group I there was $3.4 \mathrm{~mm}$ bone loss on mesial side and $3.6 \mathrm{~mm}$ on left side. In group II, there was 1.2 $\mathrm{mm}$ bone loss on mesial side and $1.4 \mathrm{~mm}$ on distal side. There were 12 dental implants failure in group I and 4 in group II.

Holahan et al. [9] reported a retrospective longitudinal 5 yr follow up study in which the question whether osteoporosis affects treatment outcome of dental implants in terms of their survival was explored. A retrospective chart review of female patients 50 yrs and older was carried out to identify patients with osteoporosis and osteopenia. Arch location of the implant, smoking status at time of dental implant placement and implant failure were noted. Implant failures were defined as dental implants that had to be removed for non infection related causes. They identified 57 patients with osteopenia (197 dental implants), 41 with osteoporosis (143 dental implants) and 94 non osteoporosis patients (306 implants). They found a ten year survival rate of $92.5 \%$ in general and no significant difference among the groups and they did not find any association of failure with arch location.

Friberg et al. [10] reported from a retrospective analysis of 13 patients ( 11 women and 2 men) with osteoporosis. Five were completely edentulous and 6 were edentulous in the maxilla, and 3 were partially edentulous. Marginal bone height (by taking a mean value of mesial and distal of the implants) was evaluated with intraoral radiographs and it was seen that at 1 the year follow-up bone loss was measured at $0.6+0.6$ $\mathrm{mm}$. A $97 \%$ success rate was observed after increased healing time and bone compaction.

\section{Conclusion}

Authors suggested that osteoporosis has great impact on survival rate of dental implant. There were more dental implants failures in these patients as compared to controls.

\section{References}

1. Jaffin RA, Berman CL. The excessive loss of Branemark fixtures in type IV bone: a 5-year analysis. J Periodontol. 1991; 62(1): 2-4. doi: 10.1902/ jop.1991.62.1.2

2. Jeffcoat $\mathrm{MK}$, Chesnut $\mathrm{CH}$ 3rd. Systemic osteoporosis and oral bone loss: evidence shows increased risk factors. J Am Dent Assoc. 1993; 124(11): 49-56. doi: 10.14219/jada.archive.1993.0225

3. Kingsmill VJ, Boyde A. Variation in the apparent density of human mandibular bone with age and dental status. J Anat. 1998; 192: 233-244. doi: 10.1046/j.1469-7580.1998.19220233.x

4. Klemetti E, Kolmakov S, Kröger H. Pantomography in assessment of the osteoporosis risk group. Scand J Dent Res. 1994; 102(1): 68-72. doi: 10.1111/j.1600-0722.1994.tb01156.x

5. Nuti N, Baldini N, D'Elia C, Gabriele G, Gennaro P, Ferrari M. Dental Implants in Osteoporotic Patients Taking Oral Bisphophonates: A Literature Review. Austin J Dent. 2017; 4(3): 1071.

6. Kanis JA. Diagnosis of osteoporosis and assessment of fracture risk. Lancet. 2002; 359(9321): 1929-1936. doi: 10.1016/S0140-6736(02)08761-5

7. Lane NE. Epidemiology, etiology, and diagnosis of osteoporosis. Am J Obstet Gynecol. 2006; 194: S3-S11. doi: 10.1016/j.ajog.2005.08.047

8. Grinspoon S, Thomas E, Pitts S, et al. Prevalence and predictive factors for regional osteopenia in women with anorexia nervosa. Ann Intern Med. 2000; 133(10): 790-794. doi: 10.7326/0003-4819-133-10-20001121000011

9. Holahan CM, Koka S, Kennel KA, et al. Effect of osteoporotic status on the survival of titanium dental implants. Int J Oral Maxillofac Implants. 2008; 23(5): 905-910.

10. Friberg B, Ekestubbe A, Mellström D, Sennerby L. Brånemark implants and osteoporosis: a clinical exploratory study. Clin Implant Dent Relat Res. 2001; 3(1): 50-56. 